\begin{tabular}{|c|l|}
\hline Title & A simple method for detection and counting of oil pal m trees using high-resolution multi spectral satellite imagery \\
\hline Author(s) & Santoso, Heri; Tani, Hiroshi; Wang, X iufeng \\
\hline Citation & $\begin{array}{l}\text { International journal of remote sensing, 37(21), 5122-5134 } \\
\text { https://doi.org/10.1080/01431161.2016.1226527 }\end{array}$ \\
\hline Issue Date & 2016-11 \\
\hline Doc URL & http://hdl.handle.net/2115/67153 \\
\hline Rights & $\begin{array}{l}\text { This is an A ccepted Manuscript of an article published by Taylor \& Francis in International Journal of Remote Sensing } \\
\text { on Published online: 23 Sep 2016, available online: http:/Www.tandfonline.com/10.1080/01431161.2016.1226527. }\end{array}$ \\
\hline Type & article (author version) \\
\hline File Information & Int. J. Remote Sens.37-21_5122-5134.pdf \\
\hline
\end{tabular}

Instructions for use 


\section{A simple method for detection and counting of oil palm trees using 2 high resolution multispectral satellite imagery}

3 Heri Santoso ${ }^{\text {a, b, }{ }^{*}}$, Hiroshi Tani ${ }^{c}$, Xiufeng Wang ${ }^{\mathrm{c}}$

4 a Indonesian Oil Palm Research Institute, Medan 20158 Indonesia;

5 b Graduate School of Agriculture, Hokkaido University, Sapporo 060-8589 Japan

6 c Research Faculty of Agriculture, Hokkaido University, Sapporo 060-8589 Japan

$7 \quad * \quad$ Corresponding author: heri@env.agr.hokudai.ac.jp; hs_jmp@yahoo.com.

8 Phone: +8111-706-3659

9

10

11

12. This is an Accepted Manuscript of an article published by Taylor \& Francis Group

13 in International Journal of Remote Sensing on 23/09/2016, available

14 online: http://dx.doi.org/10.1080/01431161.2016.1226527

15

16 


\section{A simple method for detection and counting of oil palm trees using 18 high resolution of multispectral satellite imagery}

\section{Abstract}

In the past, oil palm density has been determined by manually counting trees every year in oil palm plantations. The measurement of density provides important data related to palm productivity, fertilizer needed, weed control costs in a circle around each tree, labourers needed and needs for other activities. Manual counting requires many workers and has potential problems related to accuracy. Remote sensing provides a potential approach for counting oil palm trees. The main objective of this study is to build a robust and user-friendly method that will allow oil palm managers to count oil palm trees using a remote sensing technique. The oil palm trees analysed in this study have different ages and densities. QuickBird imagery was applied with the six pansharpening methods and was compared with panchromatic QuickBird imagery. The black and white imagery from a false colour composite of pansharpening imagery was processed in three ways: (1) oil palm tree detection, (2) delineation of the oil palm area using the red band, and (3) counting oil palm trees and accuracy assessment. For oil palm detection, we used several filters that contained a Sobel edge detector, texture analysis co-occurrence, and dilate, erode, high-pass, and opening filters. The results of this study improved upon the accuracy of several previous research studies that had an accuracy of about 90-95\%. The results in this study show (1) modified intensity-hue-saturation (IHS) Resolution Merge is suitable for 16-yearold oil palm trees and have rather high density with 100\% accuracy; (2) Colour Normalized (Brovey) is suitable for 21-year-old oil palm trees and have low density with 99.5\% accuracy; (3) Subtractive Resolution Merge is suitable for 15- and 18-year-old oil palm trees and have a rather high density with 99.8\% accuracy; (4) PC Spectral Sharpening with 99.3\% accuracy is suitable for 10-year-old oil palm trees and have low density; and (5) for all study object conditions, Colour Normalized (Brovey) and Wavelet Resolution Merge are two pansharpening methods that are 
suitable for oil palm tree extraction and counting with $98.9 \%$ and $98.4 \%$ accuracy, respectively. Keywords: filter, oil palm, oil palm counting, pansharpening, remote sensing, segmentation

\section{Introduction}

54 Oil palm density, age, management, and parent material all affect oil palm production. Oil palm tree density is one of the parameters used to determine if replanting is needed and affects oil palm production (Ng, 1972; Corley, 1973; Breure et al., 1990; Corley and Tinker, 2003; Huth et al., 2014; Bonneau et al., 2014). Therefore, one way to increase oil palm production has been to develop new varieties that are suitable for planting at high densities (Breure, 2010). Managers of oil palm plantations typically measure oil palm density manually every year. This important data can be used to estimate oil palm productivity, the amount of fertilizer needed, periodic weeding costs, and the number of workers needed, and is related to other activities (Ng, 1972; Kiama et al., 2014). Of course, counting oil palm trees manually requires many workers and has the potential problem of inaccurate counting. In the past few years, several studies have dealt with the monitoring and mapping of oil palm using remote sensing in the various contexts. The Moderate

67 Resolution Imaging Spectroradiometer (MODIS) has been used for studies on the primary productivity of oil palm trees as it is related to the global carbon balance (Cracknell et al. 2013; Tan, Kanniah, and Cracknell 2014; Cracknell et al. 2015). Tan, Kanniah, and Cracknell (2013) studied the age of oil palm trees using the Disaster Monitoring Constellation 2 and Advanced Land Observing Satellite phased array Lband synthetic aperture radar. Moreover, remote sensing has been applied for the identification and monitoring of basal stem rot disease (Lelong et al. 2010; Helmi Z M 
74 Shafri et al. 2011; Liaghat et al. 2014; Helmi Zulhaidi Mohd Shafri and Hamdan 2009;

75 Santoso et al. 2011); several research studies have used remote sensing for oil palm tree

76 detection and counting. Jusoff and Pathan (2009) used airborne hyperspectral sensing

77 with linear spectral mixture analysis, along with a mix to a pure converter and

78 Euclidean norm techniques to map individual oil palm trees. Shafri et al. (2011)

79 achieved 95\% accuracy using high spatial resolution airborne imagery with several

80 steps to discriminate oil palms from non-oil palms using spectral analysis, texture

81 analysis, edge enhancement, a segmentation process, morphological analysis and blob

82 analysis. Kattenborn et al. (2014) using unmanned aerial vehicle imagery with point

83 cloud classification (reconstruction of oil palm trees using 3D processing) and achieved

84 a mapping accuracy to $86.1 \%$ for the entire study area and $98.2 \%$ stands of dense oil

85 palm. Srestasathiern and Rakwatin (2014) using QuickBird imagery with 90\% accuracy.

86 They used a vegetation index for distinguishing oil palms from the background, and

87 then applied rank transformation, a non-maximal suppression algorithm and semi-

88 variogram analysis to determine the appropriate window size. In addition, Wong-in et al.

89 (2015) achieved 90\% accuracy using aerial images with several steps such as removing

90 non-tree components from an image, distinguishing oil palms from other components

91 using a low-pass filter and normalized cross correlation, identifying individual oil palm

92 trees, and counting the number of oil palms. Korom et al. (2014) segmented the shape

93 of oil palm canopies/crowns using WorldView-2 imagery based on watershed

94 segmentation and achieved an accuracy of about $77 \%$.

$95 \quad$ Based on previous research, oil palm plantation managers (oil palm

96 practitioners) need a simple method that is easy to implement for counting oil palm

97 trees in plantations. The main objective of this study is to build a robust and easy-to-use

98 method for counting oil palms using remote sensing. 


\section{Methods}

100 This study analysed oil palms at an oil palm estate in Medan, North Sumatra, Indonesia

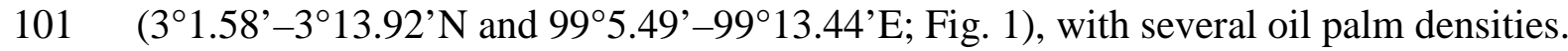

102 Basal stem rot disease in trees infected by Ganoderma boninense caused the observed

103 heterogeneity of oil palm density. QuickBird imagery archived on 4 August 2008 was

104 used in this study with bands consisting of visible red (630-690 nm), green (520-600

$105 \mathrm{~nm}$ ) and blue (450-520 nm), NIR (near infrared, 760-900 nm) and panchromatic (450-

$106900 \mathrm{~nm}$ ). Fig. 2 provides a map of the oil palm density conditions in this study area.

107 Study sites 1, 2, 3 and 4 had 16 (Fig. 2(a)), 21 (Fig. 2(b)), 15 and 18 (Fig. 2(c)), and 10

108 (Fig. 2(d)) year-old oil palms, respectively. Various conditions surrounding oil palm

109 trees, such as the density of grass and other weeds, will affect oil palm tree detection

110 and counting (Jusoff and Pathan, 2009; Shafri, et al., 2011; Kattenborn et al., 2014;

111 Wong-in et al., 2015). Therefore, the main target in the present study is to build a robust

114 oil palm tree detection, 2) delineation of the oil palm area, and 3) oil palm tree counting

115 and accuracy assessment. ENVI 5.2, ERDAS Imagine 2015, and ArcGIS 10.2.2 were

116 the types of software used in this study. As a common standard for digital image

117 processing, converting a digital number into radiance was done using ENVI 5.2. In this

118

119

120

121

122

123 method for oil palm detection and counting under any oil palm conditions and densities.

Fig. 3 shows the flow of the three-part method proposed in the present study: 1) research study, pansharpening was used for oil palm detection because this allows the shape of the oil palm canopy to be detected into detail. Johnson et al. (2012) reported that a pansharpened image has more spatial information and minimizes the distortion of spectral information of a multispectral image with lower resolution. Lin et al. (2015) reported that pansharpening can improve and increase the classification accuracy of land use and land cover using WorldView-2 imagery. 
Several pansharpening methods were used and compared with each other in the

125 present study to determine the best pansharpening method for oil palm detection.

126 Panchromatic imagery was also used in this study. Colour Normalized (Brovey), Gram-

127 Schmidt Spectral Sharpening, and PC Spectral Sharpening methods were processed

128 with ENVI 5.2. Meanwhile, Subtractive Resolution Merge, Modified HIS Resolution

129 Merge, and Wavelet Resolution Merge were processed with ERDAS Imagine 2015.

\section{$130 \quad 2.1$ Oil palm detection}

131 First, a pre-processing step was employed. All processing steps in the first part were

132 completed using ENVI 5.2. The false colour composite RGB 432 (NIR-R-Green)

133 images were built from pansharpening imagery and were then converted to a grayscale

134 image (Korom, et al., 2014). The pre-processing step continued using ENVI colour

135 tables with a grayscale image as an input file. We chose a black and white linear colour

136 table and then adjusted the stretch bottom slider to the right side and stretch top slider to

137 the left until 70-75\% of a wide slider (ENVI, 2014). The image became light in the

138 background, black in the foreground (oil palm canopy), and then the new image was

139 saved (Guijarro et al., 2011; Muller-Lunow et al., 2015). The further steps conducted

140 after pre-processing are described below:

141 - Edge enhancement. The oil palm canopy shape was detected using a Sobel edge

142 detector with approximately $75-85 \%$ of an image added back.

143 - Texture analysis in this study used co-occurrence with a mean parameter, $5 \times 5$

144 of processing windows and $3 \times 3$ of co-occurrence shift.

145 - Morphology analysis in this study consisted of two filters, a dilate filter with a 3

$146 \times 3$ kernel size and an erode filter with a $5 \times 5$ kernel size. 
- In the extracting objects step, a high-pass filter with a $9 \times 9$ kernel size was used and then we continued using an opening filter with a $5 \times 5$ kernel size. When the detected object was an oil palm tree, it was converted to a polygon.

150

151 Fig. 1. The study site is on an oil palm plantation in North Sumatra, Indonesia; A)

152 vicinity map showing the vicinity of the study site on the island of Sumatra; 2) map of

153 the study site (Source map: Indonesian Geospatial Board-

154 http://www.bakosurtanal.go.id/download/)

156 Fig. 2. Oil palm density condition in this study showing parts of (a) study site 1 (150.16 ha); (b) study site 2 (139.31 ha); (c) study site 3 (130.49 ha); (d) study site 4 (128.99 ha)

Fig. 3. The study flow chart: (I) oil palm tree detection; (II) delineation of oil palm area, and (III) oil palm tree counting and accuracy assessment The second part of the delineation of the oil palm area, a pre-processing step,

162 was needed; this was done in the same way as the first part, but using the red band

163 (Santoso et al., 2011) from pansharpening imagery as an input file. The image had 164 become lighter in the foreground (oil palm area) and darker (black) in the background.

165 After pre-processing, the morphology operation in this part was a closing filter with a 5 $166 \times 5$ or a $7 \times 7$ kernel size. The object that was detected was the oil palm area and should 167 be converted to polygon format as a masking polygon. In the final part in this study, oil 168 palm tree counting was done in ArcGIS 10.2.2 using an overlay of both polygons from

169 first and second parts; then the conversion processes were completed using polygons

170 from overlay results as point features. 


\subsection{Accuracy assessment}

172 An accuracy assessment was applied for the oil palm feature extraction (as a point

173 feature layer in GIS) and compared with the result of manual counting (Shafri, et al.,

174 2011) using on-screen digitization in five square polygons (each square polygon is $1 \mathrm{ha}$ ),

175 four of which were distributed in the fourth corners of every site area plus one polygon

176 in the centre. The number of oil palms counted manually and the number extracted

177 digitally from QuickBird imagery were selected in the five (5) square polygons using

178 ArcGIS 10.2.2; the results of these two counting methods were compared with each

179 other to determine the accuracy of oil palm detection and extraction.

\section{3. Results and discussion}

181 The proposed methods for oil palm tree detection and counting in the present study were tested in several areas with different oil palm ages and densities. Fig. 4 shows an example of the results of each process in the proposed method that was used in the

184 present study. Fig. 4(a) shows the shape of the oil palm canopy as dark-black with the

185 light areas indicating the background. An oil palm canopy takes on a star-like shape; there are outer angular shapes around the centre of the canopy. The Sobel edge detector, texture analysis, and dilate filter were applied to minimize the outer shape of the oil palm canopies (see Fig. 4(b), 4(c), and 4(d)). The erode filter produced an oil palm canopy outline as a square shape (Fig. 4(e)) and the high-pass filter sharpened this square shape (Fig. 4(f)). Moreover, the opening filter converted the square shape into

191 the object that was selected and the background is erased or left empty (Fig. $4(g)$ ). During oil palm tree extraction, several oil palm canopy/trees were not extracted

193 and some objects were also extracted that were not oil palms (Fig. 4(i)). This is caused

194 when some of the vegetation that surrounds oil palm trees has the same radiance values 
as the radiance values of oil palms. Moreover, some areas were classified as noise. In a

196 further step, the noise was reduced using the oil palm area extraction areas with the red

197 band. Meanwhile, a part of the oil palm canopy was not extracted; this was caused when

198 the oil palm canopy had some different pixel radiance values while only a small part of

199 a particular tree had the same values with oil palm radiance; however, in these cases, the

200 majority of the oil palms had the same values as the surrounding radiance values.

201 Moreover, the small part of the pixel values of oil palm radiance were erased by some

202 kernel/window size areas in filters applied in this study (Hosoi, et al., 2012; Warner et

203 al., 2006). In addition, this change affected the accuracy assessment. The oil palm area

204 extraction results will affect the accuracy of oil palm tree counting because they are

205 used to reduce noise during oil palm tree extraction.

$206 \quad 3.1$ Oil palm tree counting and accuracy assessment

207 After using a red band to reduce noise during oil palm area extraction, oil palm trees

208 could be counted from the results of the converted polygon of oil palm extraction to

209 create a point layer. The present study encompassed a total area of 548.95 ha for testing

210 the proposed methods, which were divided into four different study sites areas to

211 determine oil palm density and age. Tables $1-4$ show the ability of the method to count

212 oil palm trees and the count accuracy assessment for study sites $1-4$. We assumed the

213 manually counted values were accurate because we used QuickBird pansharpening

214 imagery to manually count trees based on screen digitized imagery of oil palm trees in

215 five square areas where each area covered 10,000 $\mathrm{m}^{2}$. Each area and pansharpening

216 method used in this study resulted in different oil palm tree counts. The research results

217 from Wyczalek and Wyczalek (2014) produced similar results while using a different

218 method of pansharpening that will affect the classification results. Tables 1-4 show the

219 potential of the four pansharpening methods for counting oil palm trees using PC 
Spectral Sharpening, Colour Normalized (Brovey), Subtractive Resolution Merge, and Modified Resolution Merge, at study sites 1-4, respectively.

Fig. 4. Example results of the proposed methods in this study: (a) black and white imagery; (b) image from Sobel applied; $(c)$ image after texture analysis; $(d)$ image after dilate filter; $(e)$ image after erode filter; $(f)$ image after high-pass filter; $(g)$ image after opening filter; $(h)$ oil palm object extraction; (i) polygon of oil palm extraction with pansharpening imagery as background

The potential of using the pansharpening method for counting oil palm trees in

different areas is shown in Table 5. Study sites 1, 2, 3, and 4 had 16, 21, 15/18, and 10year-old oil palm trees, respectively. Study sites 1, 2, 3, and 4 had rather high, low, rather high, and low oil palm density, respectively. With these conditions, the best pansharpening methods for study sites 1, 2, 3, and 4 were Modified IHS Resolution Merge pansharpening (100\% accuracy), Colour Normalized (Brovey) pansharpening (99.5\%), Subtractive Resolution Merge pansharpening (99.8\%), and PC Spectral Sharpening (99.3\%), respectively. Two pansharpening methods employed for oil palm tree extraction and counting in this study had 98.4\% and 98.9\% accuracy and were Wavelet Resolution Merge and Colour Normalized (Brovey), respectively (Table 6; Fig. 5).

When compared with the accuracy of oil palm tree counting in previous research

242 studies that used several methods, the methods proposed in the present study are

243 potentially useful for oil palm planters and plantation managers and could be adopted

244 and implemented as part of oil palm management practices. This proposed method is 245 simple and all the steps and filter are available in ENVI software. In addition, it is possible to use different image processing software that has a grayscale convert function, 
247 a foreground and background stretching function, a Sobel edge detector, and texture

248 analysis co-occurrence, as well as dilate, erode, high-pass, and opening filters.

249 We believe the accuracy achieved using the methods employed in the present

250 study is adequate for estate managers to use so they can employ remote sensing to

251 rapidly determine oil palm density. In oil palm management, if the estate has planting

252 records, especially stand maps of oil palm plantations, monitoring oil palm trees

253 individually in the field is very easy. However, sometimes oil palm plantation managers

254 need a second opinion and can accurately monitor oil palm density using imagery based

255 on remote sensing.

257 Table 1. Capability and accuracy assessment for study site 1

258

259 Table 2. Capability and accuracy assessment for study site 2

260

261 Table 3. Capability and accuracy assessment for study site 3

262 Table 4. Capability and accuracy assessment for study site 4

263

264 Table 5. The potential of the pansharpening method for oil palm tree extraction in

265 different areas

266

267

Table 6. Accuracy assessment of oil palm tree extraction

268

269 Fig. 5. Oil palm extraction and counting using Colour Normalized (Brovey) in study site

$270 \quad 2(a)$ and using Wavelet Resolution Merge in study site $3(b)$ 


\section{Conclusions}

272 The pansharpening method used with multispectral satellite imagery such as a

273 QuickBird image has potential for use in oil palm tree detection and counting. The different pansharpening methods provided different results for oil palm tree counting. The methods proposed in the present study exhibited about 98\% accuracy and provide potential methods for oil palm tree detection and counting as part of oil palm management. The methods proposed in the present study are easy to use with ENVI or other image processing software that have a grayscale conversion function, stretching foreground and background functions, a Sobel edge detector, texture analysis cooccurrence, as well as dilate, erode, high-pass, and opening filters. The proposed methods will be tested using images from unmanned aerial vehicles that many oil palm companies currently operate for surveillance and monitoring of oil palm coverage.

\section{Acknowledgement}

284 This work was supported by the Director of the Indonesian Oil Palm Research Institute.

\section{References}

286 Bonneau, Xavier, Pieter Vandessel, Maxwell Buabeng, and Charles Erhahuyi. 2014. "Early Impact of Oil Palm Planting Density on Vegetative and Oil Yield Variables in West Africa.” Ocl 21 (4): A401. doi:10.1051/ocl/2014009. (Elaeis Guineensis Jacq.) Types Suitable for Planting at High Densities.” NJAS Wageningen Journal of Life Sciences 57 (2). Royal Netherlands Society for Agriculture Sciences: 141-147. doi:10.1016/j.njas.2010.03.001.

Breure, C. J., T. Menendez, and M. S Powell. 1990. “The Effect of Planting Density on the Yield Components of Oil Palm ( Elaeis Guineensis).” Experimental Agriculture 26 (01): 117-124. doi:10.1017/S0014479700015453.

Corley, R H V, and P B Tinker. 2003. The Oil Palm. World Agriculture Series. Vol. No. 3/24. doi:10.1002/9780470750971. 
Cracknell, Arthur Philip, K D Kanniah, K P Tan, and L Wang. 2013. "Evaluation of MODIS Gross Primary Productivity and Land Cover Products for the Humid Tropics Using Oil Palm Trees in Peninsular Malaysia and Google Earth Imagery.” International Journal of Remote Sensing 34 (20): 7400-7423. doi:Doi 10.1080/01431161.2013.820367.

Cracknell, Arthur Philip, Kasturi Devi Kanniah, Kian Pang Tan, and Lei Wang. 2015. “Towards the Development of a Regional Version of MOD17 for the Determination of Gross and Net Primary Productivity of Oil Palm Trees.” International Journal of Remote Sensing 36 (1): 262-289. doi:10.1080/01431161.2014.995278.ENVI. 2014. “ENVI Classic Help.” ExelisENVI52-Classic.

Guijarro, M., G. Pajares, I. Riomoros, P. J. Herrera, X. P. Burgos-Artizzu, and A. Ribeiro. 2011. “Automatic Segmentation of Relevant Textures in Agricultural Images.” Computers and Electronics in Agriculture 75 (1). Elsevier B.V.: 75-83. doi:10.1016/j.compag.2010.09.013.

Hosoi, Fumiki, Hiroaki Matsugami, Kenichi Watanuki, Yo Shimizu, and Kenji Omasa. 2012. “Accurate Detection of Tree Apexes in Coniferous Canopies from Airborne Scanning Light Detection and Ranging Images Based on CrownExtraction Filtering.” Journal of Applied Remote Sensing 6 (1): 063502. doi:10.1117/1.JRS.6.063502.

Huth, Neil I, Murom Banabas, Paul N Nelson, and Michael Webb. 2014. “Development of an Oil Palm Cropping Systems Model: Lessons Learned and Future Directions.” Environmental Modelling \& Software 62 (0). Elsevier Ltd: 411-419. doi:http://dx.doi.org/10.1016/j.envsoft.2014.06.021.

Johnson, Brian, Ryutaro Tateishi, and Nguyen Hoan. 2012. “Satellite Image Pansharpening Using a Hybrid Approach for Object-Based Image Analysis.” ISPRS International Journal of Geo-Information 1 (3): 228-241. doi:10.3390/ijgi1030228.

Jusoff, Kamaruzaman, and Mubeena Pathan. 2009. "Mapping of Individual Oil Palm Trees Using Airborne Hyperspectral Sensing: An Overview.” Applied Physics Research 1: 15-30.

Kattenborn, T., M. Sperlich, K. Bataua, and B. Koch. 2014. “Automatic Single Palm Tree Detection in Plantations Using UAV-Based Photogrammetric Point Clouds.” International Archives of the Photogrammetry, Remote Sensing and Spatial 
Information Sciences - ISPRS Archives 40 (3): 139-144. doi:10.5194/isprsarchives-XL-3-139-2014.

Kiama, J W, V Raman, and T H H Patrick. 2014. "Low-Cost RFID-Based Palm Oil Monitoring System (PMS): First Prototype.” IOP Conference Series: Earth and Environmental Science 18: 012054. doi:10.1088/1755-1315/18/1/012054.

Korom, Alexius, M-H Phua, Y Hirata, and T Matsuura. 2014. “Extracting Oil Palm Crown from WorldView-2 Satellite Image.” IOP Conference Series: Earth and Environmental Science 18: 6. doi:10.1088/1755-1315/18/1/012044.

Lelong, Camille C D, Jean Michel Roger, Simon Brégand, Fabrice Dubertret, Mathieu Lanore, Nurul a. Sitorus, Doni a. Raharjo, and Jean Pierre Caliman. 2010. “Evaluation of Oil-Palm Fungal Disease Infestation with Canopy Hyperspectral Reflectance Data.” Sensors 10: 734-747. doi:10.3390/s100100734.

Lin, Chinsu, Chao-Cheng Wu, Khongor Tsogt, Yen-Chieh Ouyang, and Chein-I Chang. 2015. "Effects of Atmospheric Correction and Pansharpening on LULC

Müller-Linow, Mark, Francisco Pinto-Espinosa, Hanno Scharr, and Uwe Rascher. 2015.

Santoso, Heri, Totok Gunawan, Retnadi Heru Jatmiko, Witjaksana Darmosarkoro, and Budiman Minasny. 2011. "Mapping and Identifying Basal Stem Rot Disease in 233-248. doi:10.1007/s11119-010-9172-7. 
Shafri, Helmi Z. M., Nasrulhapiza Hamdan, and M. Iqbal Saripan. 2011. "SemiAutomatic Detection and Counting of Oil Palm Trees from High Spatial Resolution Airborne Imagery.” International Journal of Remote Sensing 32 (8): 2095-2115. doi:10.1080/01431161003662928.

Shafri, Helmi Z M, Mohd I Anuar, Idris a Seman and M Noor. 2011. “Spectral Discrimination of Healthy and Ganoderma-Infected Oil Palms from Hyperspectral Data.” International Journal of Remote Sensing 32 (22): 71117129. doi:10.1080/01431161.2010.519003.

Shafri, Helmi Zulhaidi Mohd, and Nasrulhapiza Hamdan. 2009. "Hyperspectral Imagery for Mapping Disease Infection in Oil Palm Plantation Using Vegetation Indices and Red Edge Techniques.” American Journal of Applied Sciences 6 (6): 1031-1035. doi:10.3844/ajassp.2009.1031.1035.

Srestasathiern, Panu, and Preesan Rakwatin. 2014. “Oil Palm Tree Detection with High Resolution Multi-Spectral Satellite Imagery.” Remote Sensing 6 (10): 9749_ 9774. doi:10.3390/rs6109749.

Tan, Kian Pang, K D Kanniah, and a P Cracknell. 2013. "Use of UK-DMC 2 and ALOS PALSAR for Studying the Age of Oil Palm Trees in Southern Peninsular Malaysia.” International Journal of Remote Sensing 34 (November 2013): 7424-7446. doi:10.1080/01431161.2013.822601.

Tan, Kian Pang, Kasturi Devi Kanniah, and Arthur Philip Cracknell. 2014. “On the Upstream Inputs into the MODIS Primary Productivity Products Using Biometric Data from Oil Palm Plantations.” International Journal of Remote Sensing Vol. 35, N (August 2014): 37-41. doi:10.1080/01431161.2014.889865.

Warner, Timothy A., James B. McGraw, and Rick Landenberger. 2006. "Segmentation and Classification of High Resolution Imagery for Mapping Individual Species in a Closed Canopy, Deciduous Forest.” Science in China, Series E: Technological Sciences 49 (SUPPL. 1): 128-139. doi:10.1007/s11431-0068114-0.

Wong-in, Teerawut, Tonphong Kaewkongka, Nagul Cooharojananone, and Rajalida Lipikorn. 2015. “Automatic Oil Palm Detection and Identification from MultiScale Clustering and Normalized Cross Correlation.” In , 403-410. Springer Berlin Heidelberg. doi:10.1007/978-3-662-47200-2_43. 
399

400

401

402

403

404

405

406

407

408

409

410

411

412

413

414

415

416

417

418

419

420

421

422

423

424

425
Wyczałek, Ireneusz, and Wyczałek Elżbieta. 2013. "Studies on Pansharpening and Object-Based Classification of Worldview-2 Multispectral Image.” Archives of Photogrammetry, Cartography and Remote Sensing, no. Monograph: 109-117. 
426 Table 1. Capability and accuracy assessment for study site 1

\begin{tabular}{|c|c|c|c|c|c|c|c|}
\hline Method & $\begin{array}{l}\text { Area } \\
\text { (ha) }\end{array}$ & $\begin{array}{l}\text { Total of } \\
\text { oil palm } \\
\text { extraction }\end{array}$ & $\begin{array}{l}\text { Polygon } \\
\text { test (ha) }\end{array}$ & $\begin{array}{c}\text { Oil } \\
\text { palm } \\
\text { counted } \\
\text { manually }\end{array}$ & $\begin{array}{l}\text { Oil palm } \\
\text { extraction }\end{array}$ & $\begin{array}{l}\text { Diffe- } \\
\text { rence }\end{array}$ & $\begin{array}{c}\text { Accuracy (\%) } \\
\text { (compared with } \\
\text { counted manually } \\
\text { data) }\end{array}$ \\
\hline Panchromatic & 150.16 & 15,421 & 5 & 514 & 529 & (15) & 97.2 \\
\hline $\begin{array}{l}\text { Gram Schmidt Spectral } \\
\text { Sharpening }\end{array}$ & 150.16 & 13,306 & 5 & 514 & 483 & 31 & 94.0 \\
\hline $\begin{array}{l}\text { PC Spectral } \\
\text { Sharpening }\end{array}$ & 150.16 & 12,125 & 5 & 514 & 439 & 75 & 85.4 \\
\hline $\begin{array}{l}\text { Colour Normalized } \\
\text { (Brovey) }\end{array}$ & 150.16 & 14,107 & 5 & 514 & 485 & 29 & 94.4 \\
\hline $\begin{array}{l}\text { Subtractive } \\
\text { Resolution Merge }\end{array}$ & 150.16 & 13,216 & 5 & 514 & 475 & 39 & 92.4 \\
\hline $\begin{array}{l}\text { Modified Intensity- } \\
\text { Hue-Saturation } \\
\text { Resolution Merge }\end{array}$ & 150.16 & 14,471 & 5 & 514 & 514 & - & 100.0 \\
\hline $\begin{array}{l}\text { Wavelet Resolution } \\
\text { Merge }\end{array}$ & 150.16 & 13,601 & 5 & 514 & 486 & 28 & 94.6 \\
\hline
\end{tabular}

427

428 
429 Table 2. Capability and accuracy assessment for study site 2

\begin{tabular}{|c|c|c|c|c|c|c|c|}
\hline Method & $\begin{array}{l}\text { Area } \\
\text { (ha) }\end{array}$ & $\begin{array}{l}\text { Total of } \\
\text { oil palm } \\
\text { extraction }\end{array}$ & $\begin{array}{l}\text { Polygon } \\
\text { test (ha) }\end{array}$ & $\begin{array}{c}\text { Oil } \\
\text { palm } \\
\text { counted } \\
\text { manually }\end{array}$ & $\begin{array}{l}\text { Oil palm } \\
\text { extraction }\end{array}$ & $\begin{array}{l}\text { Diffe- } \\
\text { rence }\end{array}$ & $\begin{array}{c}\text { Accuracy (\%) } \\
\text { (compared with } \\
\text { counted manually } \\
\text { data) }\end{array}$ \\
\hline Panchromatic & 139.31 & 11,263 & 5 & 400 & 433 & (33) & 92.4 \\
\hline $\begin{array}{l}\text { Gram Schmidt Spectral } \\
\text { Sharpening }\end{array}$ & 139.31 & 9,604 & 5 & 400 & 370 & 30 & 92.5 \\
\hline $\begin{array}{l}\text { PC Spectral } \\
\text { Sharpening }\end{array}$ & 139.31 & 9,564 & 5 & 400 & 375 & 25 & 93.8 \\
\hline $\begin{array}{l}\text { Colour Normalized } \\
\text { (Brovey) }\end{array}$ & 139.31 & 10,703 & 5 & 400 & 398 & 2 & 99.5 \\
\hline $\begin{array}{l}\text { Subtractive } \\
\text { Resolution Merge }\end{array}$ & 139.31 & 9,668 & 5 & 400 & 369 & 31 & 92.3 \\
\hline $\begin{array}{l}\text { Modified Intensity- } \\
\text { Hue-Saturation } \\
\text { Resolution Merge }\end{array}$ & 139.31 & 10,957 & 5 & 400 & 415 & (15) & 96.4 \\
\hline $\begin{array}{l}\text { Wavelet Resolution } \\
\text { Merge }\end{array}$ & 139.31 & 10,111 & 5 & 400 & 392 & 8 & 98.0 \\
\hline
\end{tabular}


432 Table 3. Capability and accuracy assessment for study site 3

\begin{tabular}{|c|c|c|c|c|c|c|c|}
\hline Method & $\begin{array}{l}\text { Area } \\
\text { (ha) }\end{array}$ & $\begin{array}{l}\text { Total of } \\
\text { oil palm } \\
\text { extraction }\end{array}$ & $\begin{array}{l}\text { Polygon } \\
\text { test (ha) }\end{array}$ & $\begin{array}{l}\text { Oil palm } \\
\text { counted } \\
\text { manually }\end{array}$ & $\begin{array}{l}\text { Oil palm } \\
\text { extraction }\end{array}$ & $\begin{array}{l}\text { Diffe- } \\
\text { rence }\end{array}$ & $\begin{array}{c}\text { Accuracy (\%) } \\
\text { (compared with } \\
\text { counted manually } \\
\text { data) }\end{array}$ \\
\hline Panchromatic & 130.49 & 12,869 & 5 & 471 & 495 & (24) & 95.2 \\
\hline $\begin{array}{l}\text { Gram Schmidt Spectral } \\
\text { Sharpening }\end{array}$ & 130.49 & 11,629 & 5 & 471 & 454 & 17 & 96.4 \\
\hline $\begin{array}{l}\text { PC Spectral } \\
\text { Sharpening }\end{array}$ & 130.49 & 12,261 & 5 & 471 & 465 & 6 & 98.7 \\
\hline $\begin{array}{l}\text { Colour Normalized } \\
\text { (Brovey) }\end{array}$ & 130.49 & 13,000 & 5 & 471 & 495 & (24) & 95.2 \\
\hline $\begin{array}{l}\text { Subtractive } \\
\text { Resolution Merge }\end{array}$ & 130.49 & 12,297 & 5 & 471 & 472 & (1) & 99.8 \\
\hline $\begin{array}{l}\text { Modified Intensity- } \\
\text { Hue-Saturation } \\
\text { Resolution Merge }\end{array}$ & 130.49 & 12,817 & 5 & 471 & 493 & (22) & 95.5 \\
\hline $\begin{array}{l}\text { Wavelet Resolution } \\
\text { Merge }\end{array}$ & 130.49 & 12,399 & 5 & 471 & 469 & 2 & 99.6 \\
\hline
\end{tabular}


435 Table 4. Capability and accuracy assessment for study site 4

\begin{tabular}{|c|c|c|c|c|c|c|c|}
\hline Method & $\begin{array}{l}\text { Area } \\
\text { (ha) }\end{array}$ & $\begin{array}{l}\text { Total of } \\
\text { oil palm } \\
\text { extraction }\end{array}$ & $\begin{array}{l}\text { Polygon } \\
\text { test (ha) }\end{array}$ & $\begin{array}{c}\text { Oil } \\
\text { palm } \\
\text { counted } \\
\text { manually }\end{array}$ & $\begin{array}{l}\text { Oil palm } \\
\text { extraction }\end{array}$ & $\begin{array}{l}\text { Diffe- } \\
\text { rence }\end{array}$ & $\begin{array}{c}\text { Accuracy (\%) } \\
\text { (compared with } \\
\text { counted manually } \\
\text { data) }\end{array}$ \\
\hline Panchromatic & 128.99 & 13,183 & 5 & 449 & 514 & (65) & 87.4 \\
\hline $\begin{array}{l}\text { Gram Schmidt Spectral } \\
\text { Sharpening }\end{array}$ & 128.99 & 11,414 & 5 & 449 & 464 & (15) & 96.8 \\
\hline $\begin{array}{l}\text { PC Spectral } \\
\text { Sharpening }\end{array}$ & 128.99 & 11,137 & 5 & 449 & 446 & 3 & 99.3 \\
\hline $\begin{array}{l}\text { Colour Normalized } \\
\text { (Brovey) }\end{array}$ & 128.99 & 12,127 & 5 & 449 & 476 & (27) & 94.3 \\
\hline $\begin{array}{l}\text { Subtractive } \\
\text { Resolution Merge }\end{array}$ & 128.99 & 11,272 & 5 & 449 & 444 & 5 & 98.9 \\
\hline $\begin{array}{l}\text { Modified Intensity- } \\
\text { Hue-Saturation } \\
\text { Resolution Merge }\end{array}$ & 128.99 & 12,722 & 5 & 449 & 499 & (50) & 90.0 \\
\hline $\begin{array}{l}\text { Wavelet Resolution } \\
\text { Merge }\end{array}$ & 128.99 & 11,579 & 5 & 449 & 458 & (9) & 98.0 \\
\hline
\end{tabular}

436 
438 Table 5. The potential of the pansharpening method for oil palm tree extraction in 439 different areas

\begin{tabular}{lcccc}
\hline \multirow{2}{*}{ Method } & \multicolumn{2}{c}{ Accuracy (\%) (compared with counted manually data) } \\
\cline { 2 - 5 } & Area 1 & Area 2 & Area 3 & Area 4 \\
\hline Panchromatic & 97.2 & 92.4 & 95.2 & 87.4 \\
Gram Schmidt Spectral Sharpening & 94.0 & 92.5 & 96.4 & 96.8 \\
PC Spectral Sharpening & 85.4 & 93.8 & 98.7 & $\mathbf{9 9 . 3}$ \\
Colour Normalized (Brovey) & 94.4 & $\mathbf{9 9 . 5}$ & 95.2 & 94.3 \\
Subtractive Resolution Merge & 92.4 & 92.3 & $\mathbf{9 9 . 8}$ & 98.9 \\
Modified Intensity-Hue-Saturation & $\mathbf{1 0 0 . 0}$ & 96.4 & 95.5 & 90.0 \\
Resolution Merge & & & 99.6 & 98.0 \\
Wavelet Resolution Merge & 94.6 & 98.0 & &
\end{tabular}

440 Highlighted are the results of highest accuracy in the same column.

441 
442 Table 6. Accuracy assessment of oil palm tree extraction

\begin{tabular}{|c|c|c|c|c|c|c|c|}
\hline Method & $\begin{array}{l}\text { Area } \\
\text { (ha) }\end{array}$ & $\begin{array}{l}\text { Total of } \\
\text { oil palm } \\
\text { extraction }\end{array}$ & $\begin{array}{l}\text { Polygon } \\
\text { test (ha) }\end{array}$ & $\begin{array}{l}\text { Oil palm } \\
\text { counted } \\
\text { manually }\end{array}$ & $\begin{array}{l}\text { Oil palm } \\
\text { extraction }\end{array}$ & $\begin{array}{l}\text { Diffe- } \\
\text { rence }\end{array}$ & $\begin{array}{c}\text { Accuracy (\%) } \\
\text { (compared with } \\
\text { counted manually } \\
\text { data) }\end{array}$ \\
\hline Panchromatic & 548.95 & 52,736 & 20 & 1,834 & 1,971 & (137) & 93.0 \\
\hline $\begin{array}{l}\text { Gram Schmidt Spectral } \\
\text { Sharpening }\end{array}$ & 548.95 & 45,953 & 20 & 1,834 & 1,771 & 63 & 96.6 \\
\hline $\begin{array}{l}\text { PC Spectral } \\
\text { Sharpening }\end{array}$ & 548.95 & 45,087 & 20 & 1,834 & 1,725 & 109 & 94.1 \\
\hline $\begin{array}{l}\text { Colour Normalized } \\
\text { (Brovey) }\end{array}$ & 548.95 & 49,937 & 20 & 1,834 & 1,854 & (20) & 98.9 \\
\hline $\begin{array}{l}\text { Subtractive } \\
\text { Resolution Merge }\end{array}$ & 548.95 & 46,453 & 20 & 1,834 & 1,760 & 74 & 96.0 \\
\hline $\begin{array}{l}\text { Modified HIS } \\
\text { Resolution Merge }\end{array}$ & 548.95 & 50,967 & 20 & 1,834 & 1,921 & (87) & 95.5 \\
\hline $\begin{array}{l}\text { Wavelet Resolution } \\
\text { Merge }\end{array}$ & 548.95 & 47,690 & 20 & 1,834 & 1,805 & 29 & 98.4 \\
\hline
\end{tabular}

443 Highlighted are results of highest accuracy.

444

445

446

447

448

449

450

451

452

453

454

455

456

457

458 


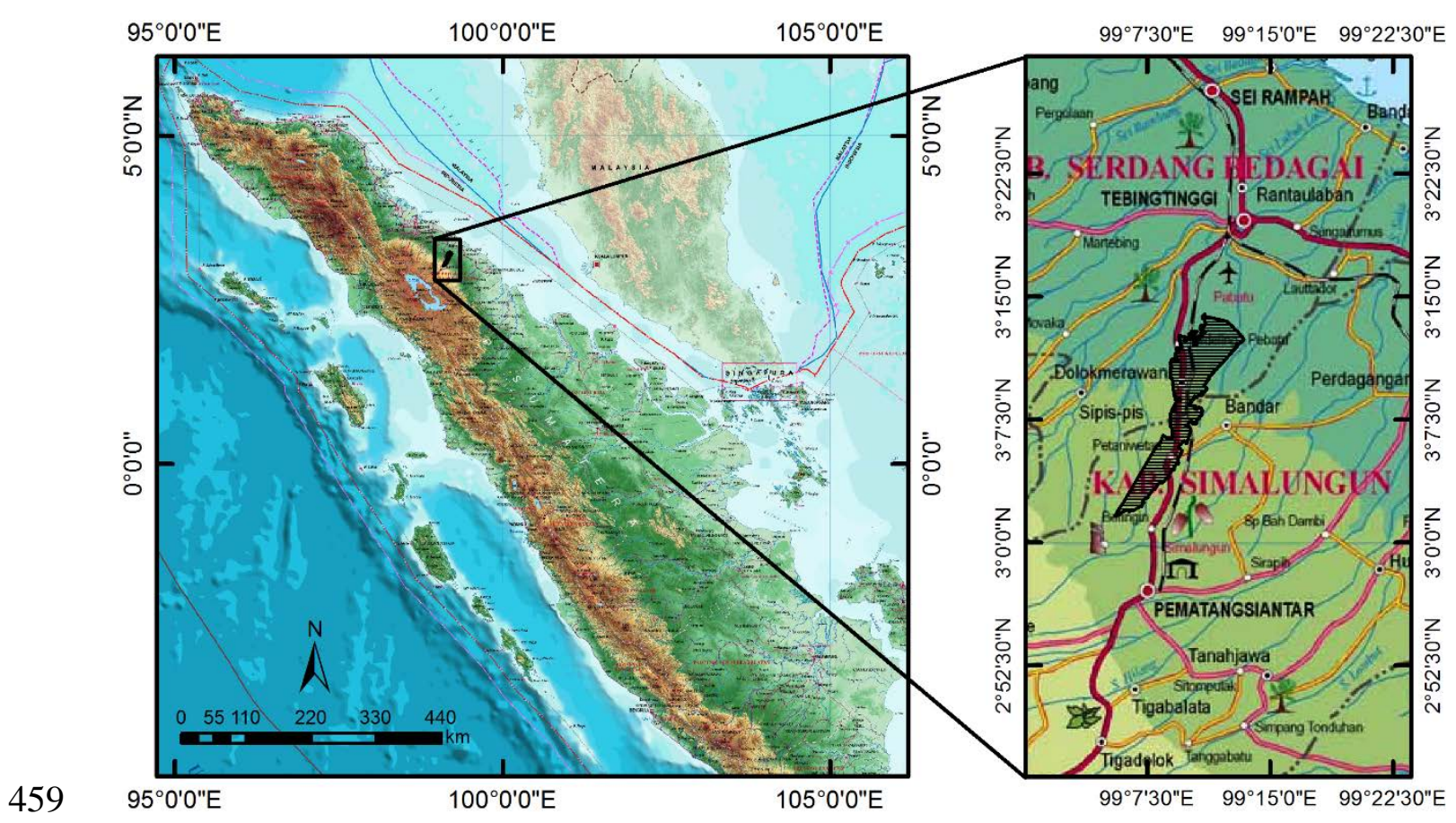

460 Fig. 1. The study site is on an oil palm plantation in North Sumatra, Indonesia; A)

461 vicinity map showing the vicinity of the study site on the island of Sumatra; 2) map of

462 the study site (Source map: Indonesian Geospatial Board-

463 http://www.bakosurtanal.go.id/download/)

464 


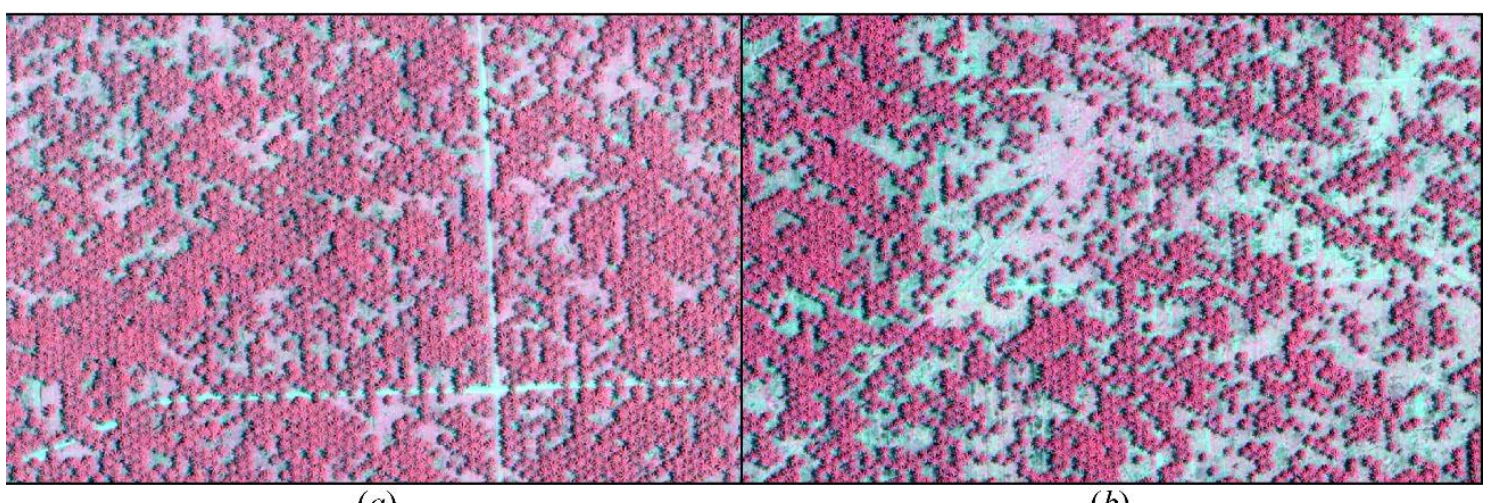

(a)

(b)

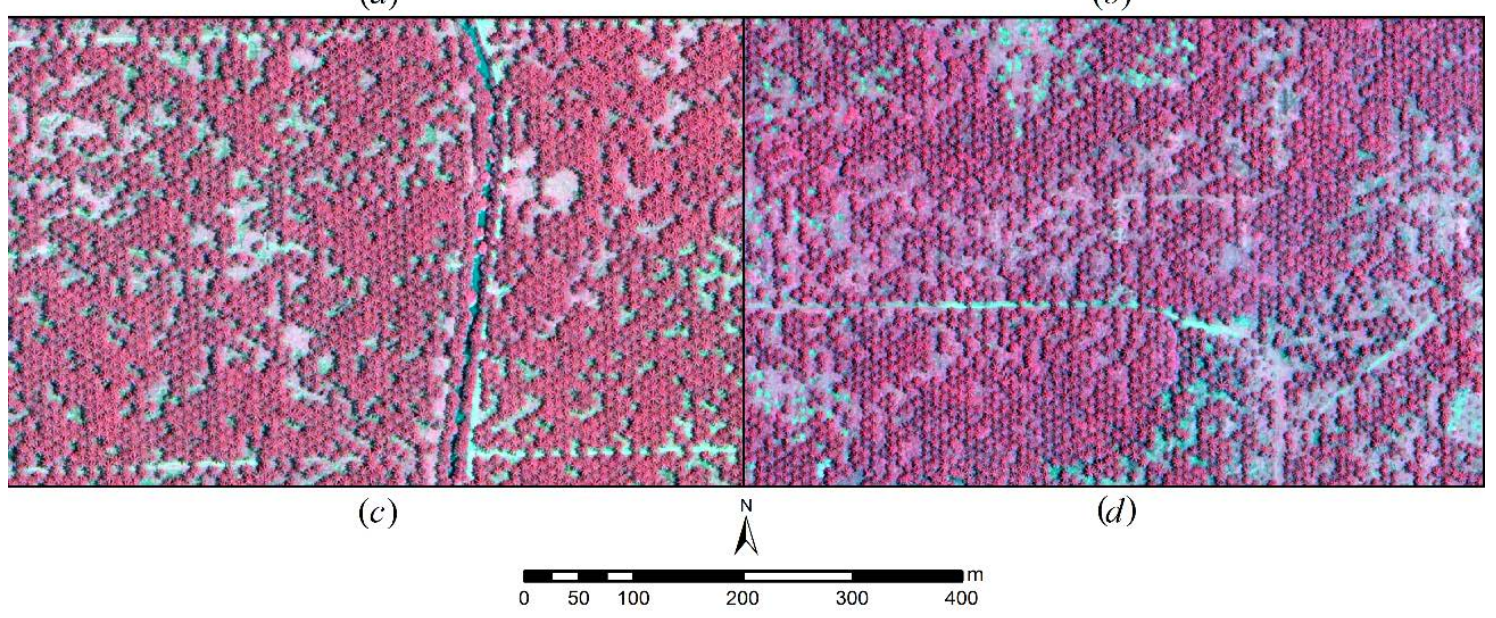

465

466 Fig. 2. Oil palm density condition in this study showing parts of (a) study site 1 (150.16 467 ha); (b) study site 2 (139.31 ha); (c) study site 3 (130.49 ha); (d) study site 4 (128.99 ha) 


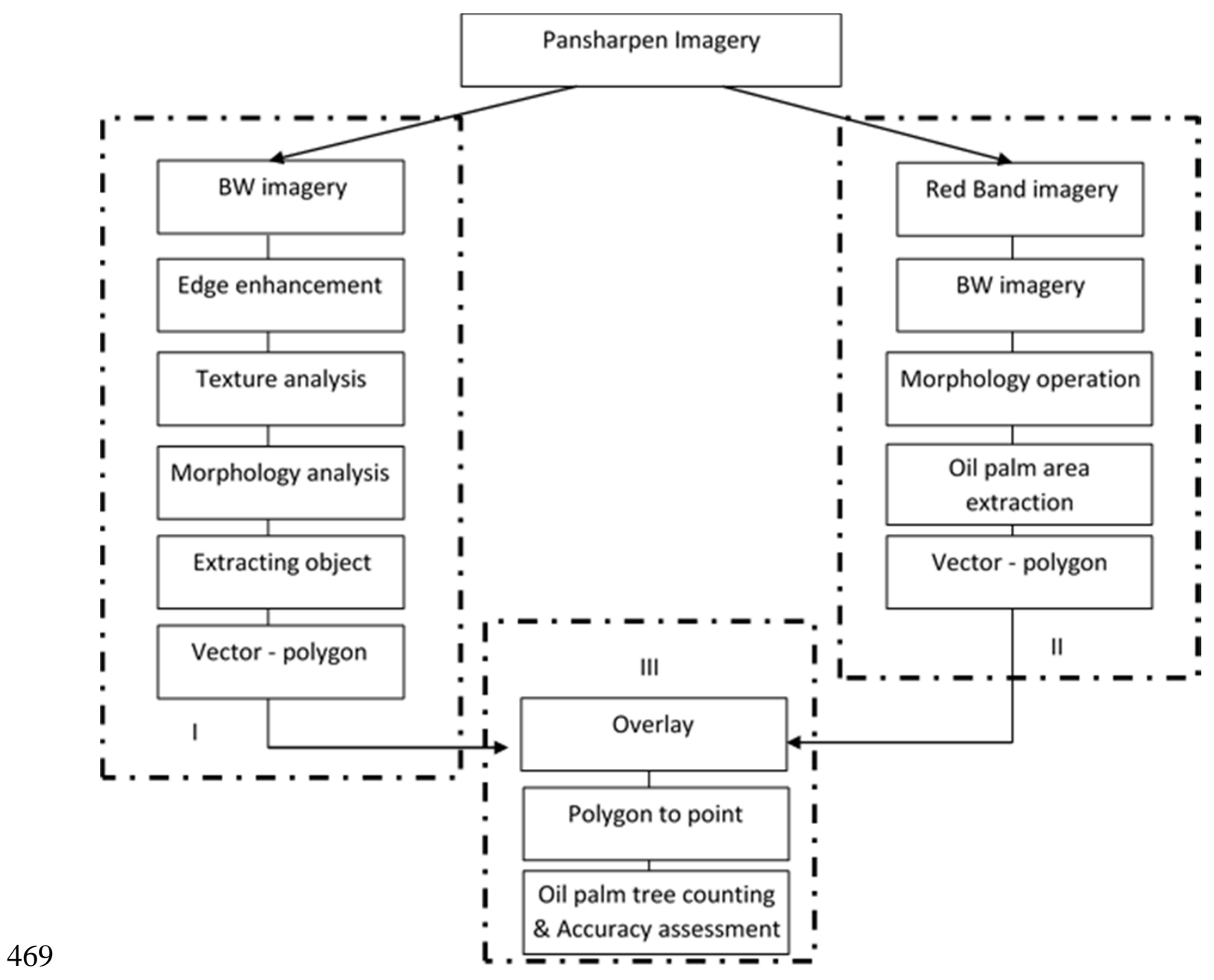

470 Fig. 3. The study flow chart: (I) oil palm tree detection; (II) delineation of oil palm area, 471 and (III) oil palm tree counting and accuracy assessment 


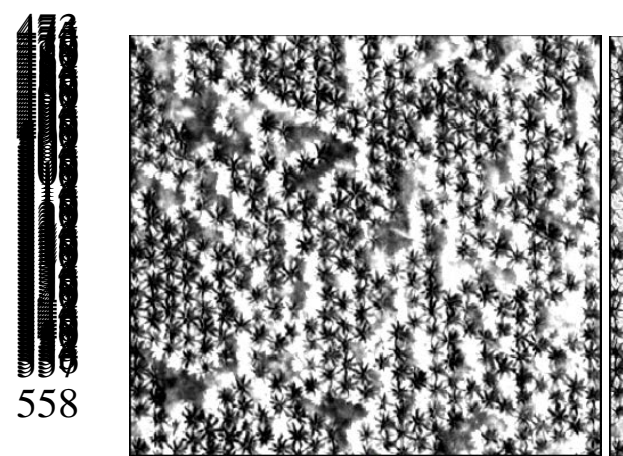

(a)

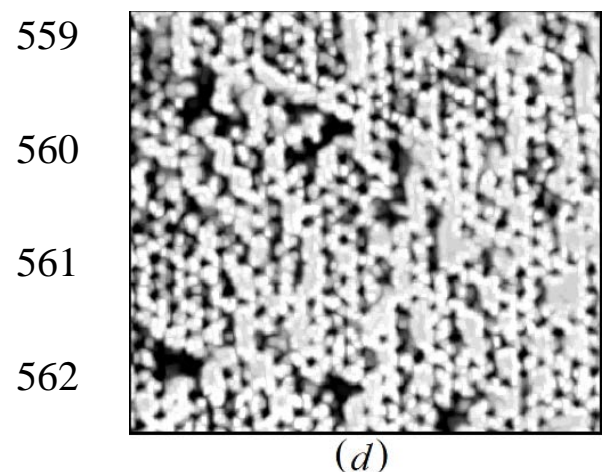

563

564

565

566

567

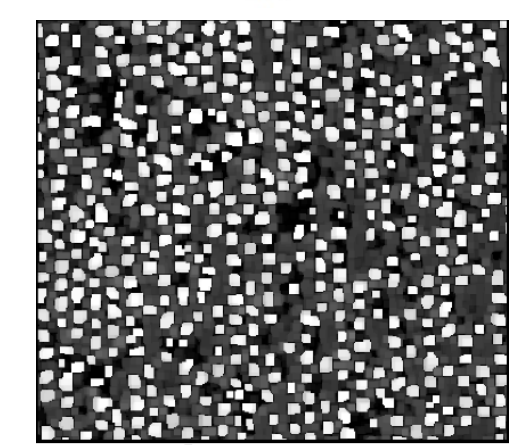

2040
0
0

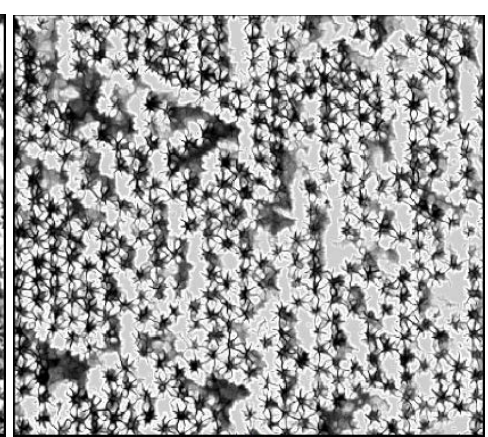

(b)

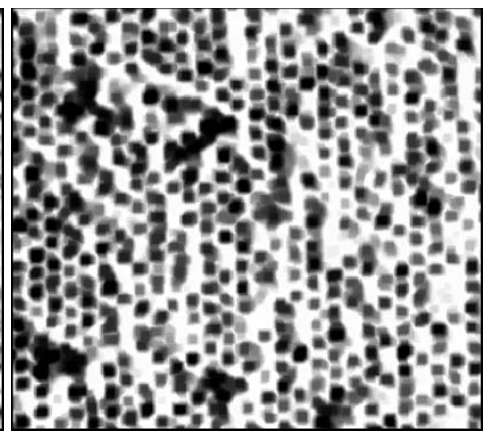

(e)

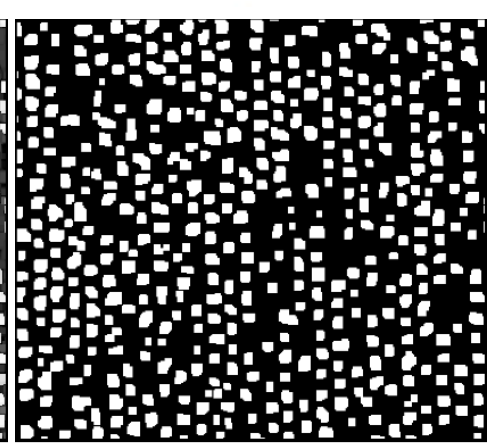

(h)

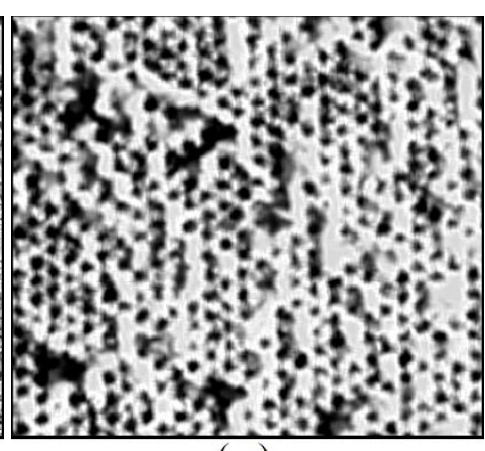

(c)

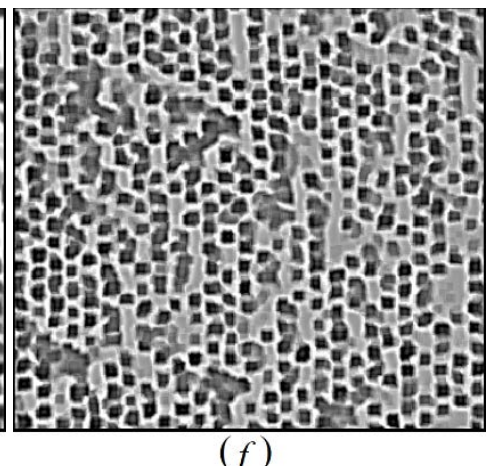

( $f)$

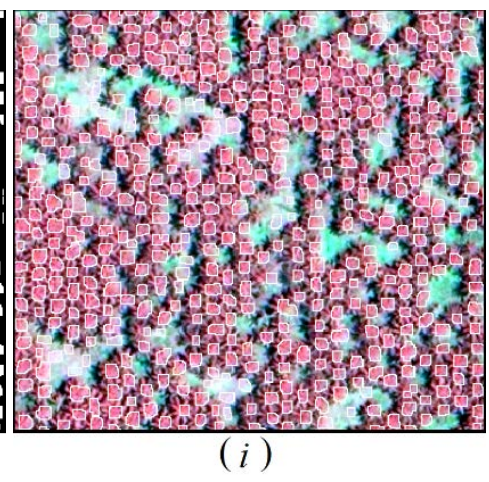

568 Fig. 4. Example results of the proposed methods in this study: (a) black and white (BW)

569 imagery; (b) image from Sobel applied; $(c)$ image after texture analysis; $(d)$ image after

570 dilate filter; $(e)$ image after erode filter; $(f)$ image after high-pass filter; $(g)$ image after

571 opening filter; $(h)$ oil palm object extraction; (i) polygon of oil palm extraction with

572 pansharpening imagery as background 


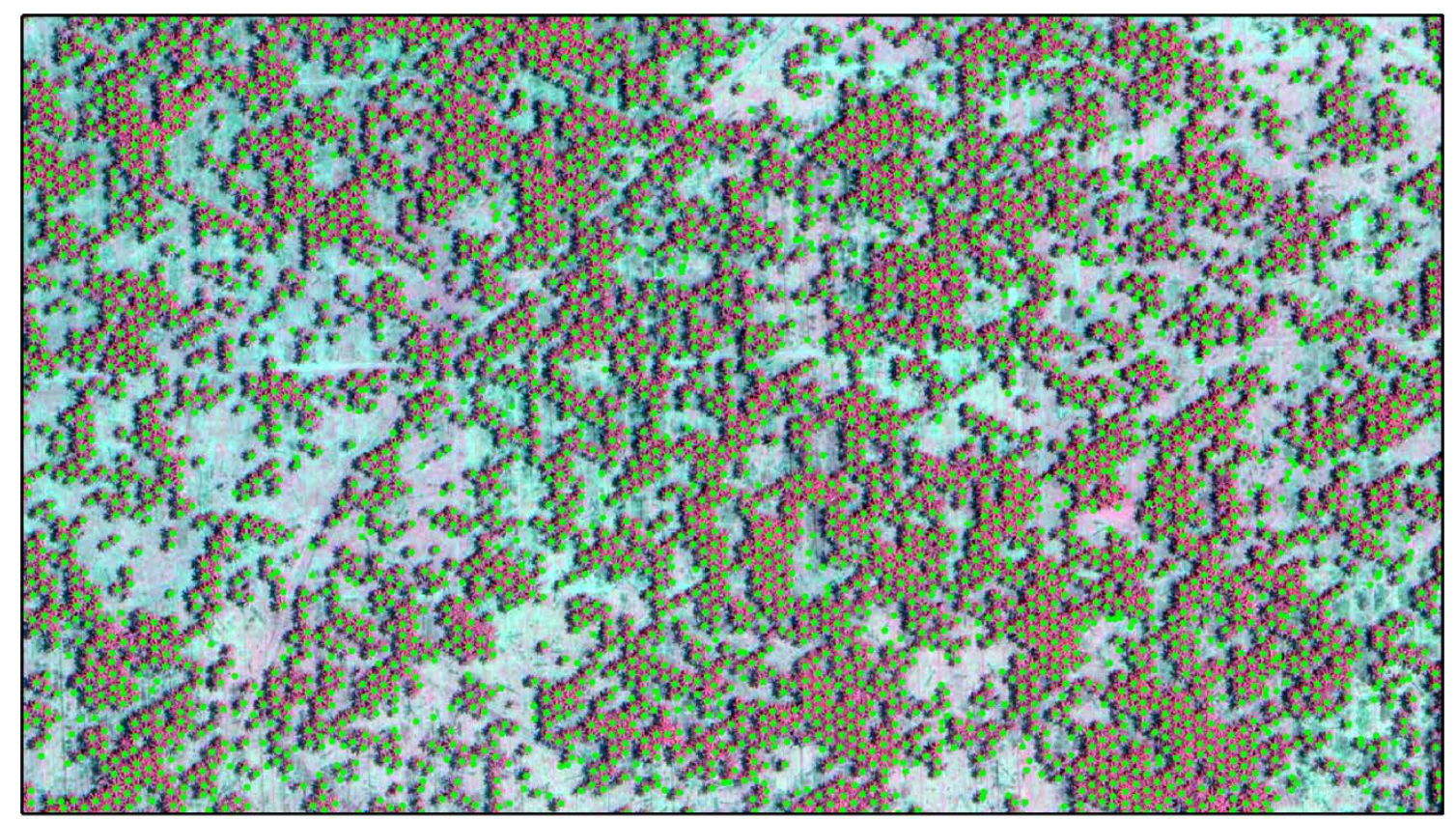

(a)

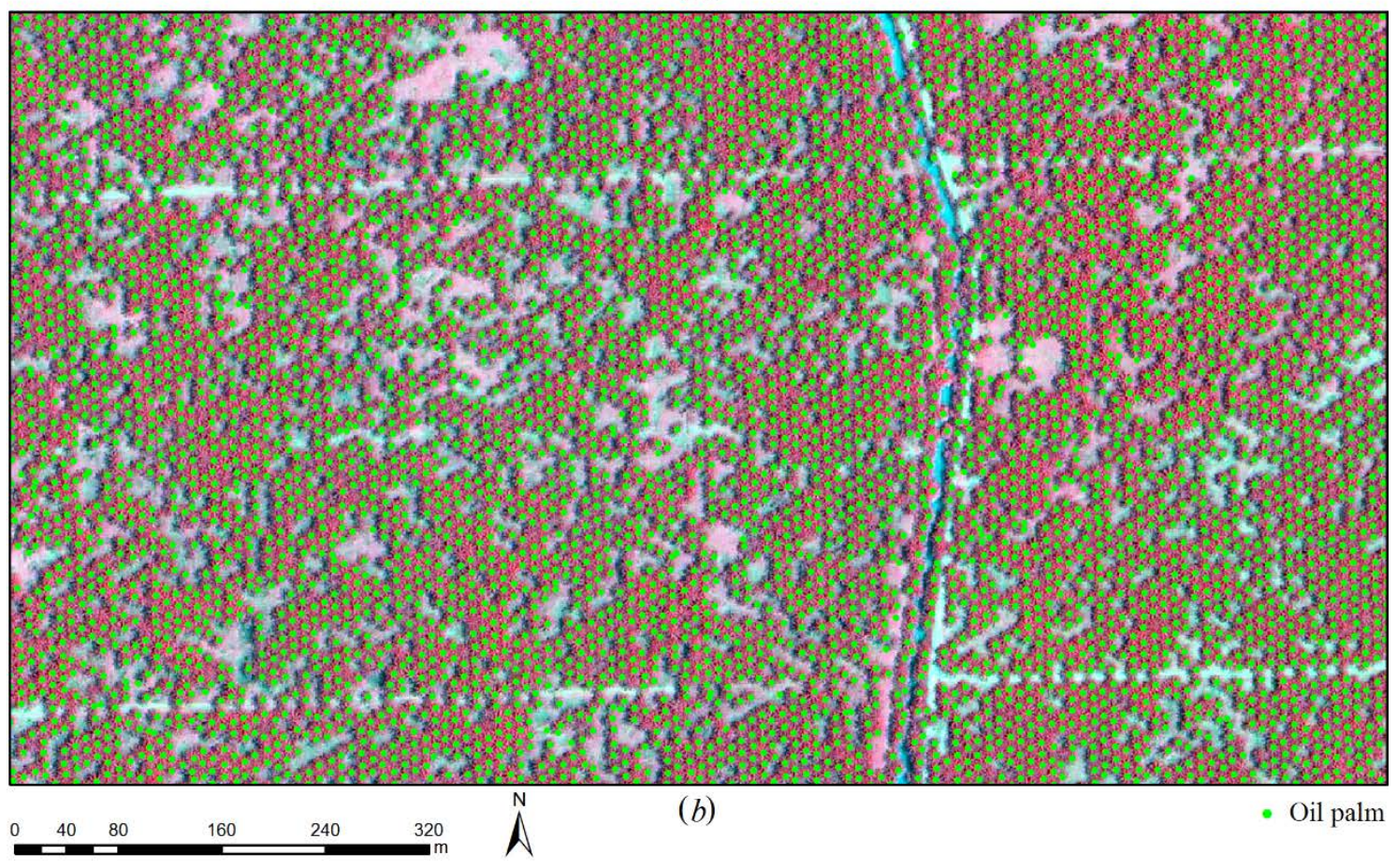

575 Fig. 5. Oil palm extraction and counting using Colour Normalized (Brovey) in study site

$576 \quad 2(a)$ and using Wavelet Resolution Merge in study site 3 (b)

577

578

579

580 
581

582

583

584

585

586 